\title{
Managing ankle ligament sprains and tears: current opinion
}

\author{
This article was published in the following Dove Press journal: \\ Open Access Journal of Sports Medicine \\ 2 March 2016 \\ Number of times this article has been viewed
}

\author{
Ryan P McGovern' \\ RobRoy L Martin ${ }^{1,2}$ \\ 'Department of Physical Therapy, \\ Rangos School of Health Sciences, \\ Duquesne University, ${ }^{2}$ Centers for \\ Sports Medicine - University of \\ Pittsburgh, Pittsburgh, PA, USA
}

Correspondence: RobRoy L Martin Department of Physical Therapy, Rangos School of Health Sciences, Duquesne University, I I 4 Rangos School of Health Sciences, Pittsburgh, PA 15282, USA

Tel + | 4|2396 I8I|

Fax + I 4I23964399

Email martinr280@duq.edu

\begin{abstract}
The purpose of this paper is to present a current review of pathoanatomical features, differential diagnosis, objective assessment, intervention, and clinical course associated with managing lateral ankle ligament sprains. Proper diagnosis and identification of affected structures should be obtained through history and objective assessment. From this information, an individualized evidence-based intervention plan can be developed to enable recovery while decreasing the risk of reinjury. An appropriate evaluation is needed not only to determine the correct diagnosis but also to allow for grading and determining the prognosis of the injury in those with an acute lateral ankle sprain. Examination should include an assessment of impairments as well as a measure of activity and participation. Evidence-based interventions for those with an acute lateral ankle sprain should include weight bearing with bracing, manual therapy, progressive therapeutic exercises, and cryotherapy. For those with chronic ankle instability (CAI), interventions should include manual therapy and a comprehensive rehabilitation program. It is essential to understand the normal clinical course for athletes who sustain a lateral ankle sprain as well as risk factors for an acute injury and CAI. Risk factors for both an acute lateral ankle sprain and CAI include not using an external support and not participating in an appropriate exercise program. Incorporating the latest evidence-based rehabilitation techniques provides the best course of treatment for athletes with an acute ankle sprain or CAI.
\end{abstract}

Keywords: reinjury, chronic ankle instability, rehabilitation techniques, diagnosis, intervention, athlete

\section{Introduction}

Ankle sprains continue to be an area of interest in sports medicine. Although research has produced advancements in prevention, diagnosis, and management, recent epidemiology studies have revealed that lateral ankle sprains remain a dominant sports injury. ${ }^{1}$ Ankle sprains are common among physically active individuals, particularly those who participate in court and team sports. ${ }^{2}$ Reinjury is also problematic in those engaging in high-risk sports, such as basketball. ${ }^{3}$ Ankle injuries were found to account for $\sim 14 \%$ of all sports-related orthopedic emergency visits, ${ }^{4}$ with a lateral ankle sprain being the most common of these injuries. ${ }^{2}$ It should be noted that the overall incidence of lateral ankle sprains may be underestimated as $\sim 50 \%$ of those who sustain an ankle sprain do not seek medical attention. ${ }^{5-7}$ Appropriate management of an athlete with a lateral ankle sprain is vital to successful recovery. Proper diagnosis and identification of affected structures must be obtained through history and objective assessment. From this information, an individualized evidence-based intervention plan can be developed to enable recovery while decreasing the risk of reinjury. The purpose of this paper is to 
present a current review related to pathoanatomical features, differential diagnosis, objective assessment, intervention, and clinical course associated with managing lateral ankle ligament sprains.

\section{Pathoanatomical features}

The first step in managing ligament sprains of the ankle is an understanding of the normal anatomy as well as pathoanatomical features of the ankle region. The ankle region consists of three major articulations: talocrural, subtalar, and distal tibiofibular syndesmosis. Damage to the passive ligament structures of the lateral ankle is termed lateral ankle sprain. ${ }^{8}$ The lateral ligaments of the talocrural joint consist of the anterior talofibular ligament (ATFL), the calcaneofibular ligament (CFL), and the posterior talofibular ligament. The most common mechanism of injury for a lateral ankle sprain is forefoot adduction, hindfoot inversion, and tibial external rotation with the ankle in plantar flexion. One or more of the lateral ligaments can be involved in this type of injury, depending on the amount and direction of force. The ATFL has been found to be the weakest and most commonly injured ligament, followed by CFL and the posterior talofibular ligament injuries, respectively. ${ }^{8}$ Approximately $70 \%$ of all lateral ankle sprains involve isolated ATFL injuries. ${ }^{2}$ While a lateral ankle sprain is the most common traumatic sports-related ankle injury, it is necessary to be aware of other diagnoses that can be mistaken for and/or occur with a lateral ankle sprain.

In addition to a lateral ankle sprain, differential diagnosis in those with a traumatic ankle injury should include, but not be limited to, fracture, high-ankle sprain, cuboid syndrome, medial-ankle sprain, and osteochondral (OCD) lesion. The
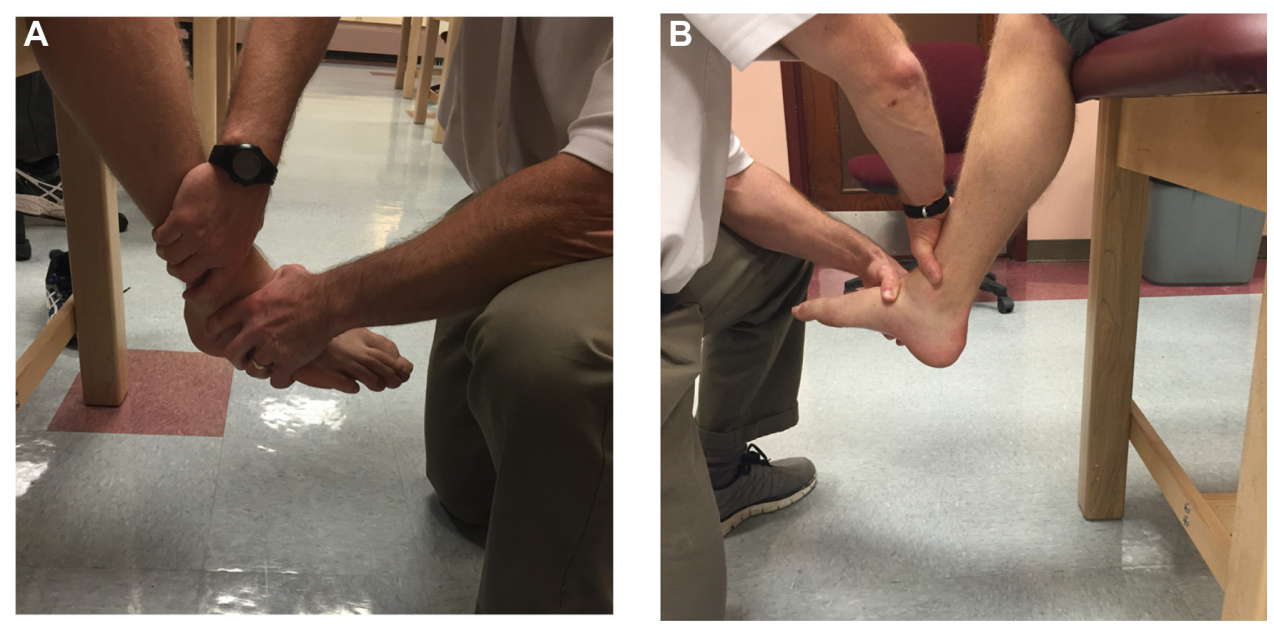

Ottawa ankle rules are used to rule out a fracture, and radiographs are indicated if there is pain within the malleolar zone that is accompanied by any of the following findings: (1) tenderness along the tip of the posterior edge of the lateral malleolus, (2) tenderness over the medial malleolus, and/or (3) the inability of the patient to bear weight for a minimum four steps. ${ }^{9}$ Radiographs are also indicated, according to the Ottawa ankle rules, if there is pain in the mid-foot area accompanied by any of the following findings: (1) tenderness with palpation at the base of the fifth metatarsal, (2) tenderness over the navicular bone, and/or (3) an inability to bear weight for a minimum four steps. ${ }^{9}$ Injury to the distal tibiofibular syndesmosis is commonly termed high-ankle sprain and can occur with external rotation of the foot and/or extreme ankle dorsiflexion. ${ }^{10,11}$ Pain and swelling extending proximal to the anterior tibiofibular ligament as well as at the posteromedial ankle regions are usually present in those with a high-ankle sprain. ${ }^{12,13}$ Palpation of the interosseous space $^{13}$ and use of the squeeze, external rotation, and dorsiflexion compression tests can be useful in the diagnostic process. ${ }^{12}$ However, a recent study found that in those with an acute ankle sprain, a clinical examination may be inadequate in detecting high-ankle sprains. ${ }^{14}$ Tenderness at the medial ankle that is associated with a mechanism of injury that includes pronation-abduction, pronation-external rotation, or supination-external rotation of the foot injury can be indicative of a medial-ankle sprain. ${ }^{15}$ Depending on the severity of the eversion injury, pain on the lateral side of the ankle can also be present due to impingement of the talus and lateral malleolus. Diagnosis of a medial-ankle sprain can be attained by using the eversion stress and Kleiger's tests (Figure 1). When an ankle is plantar flexed and an excessive 

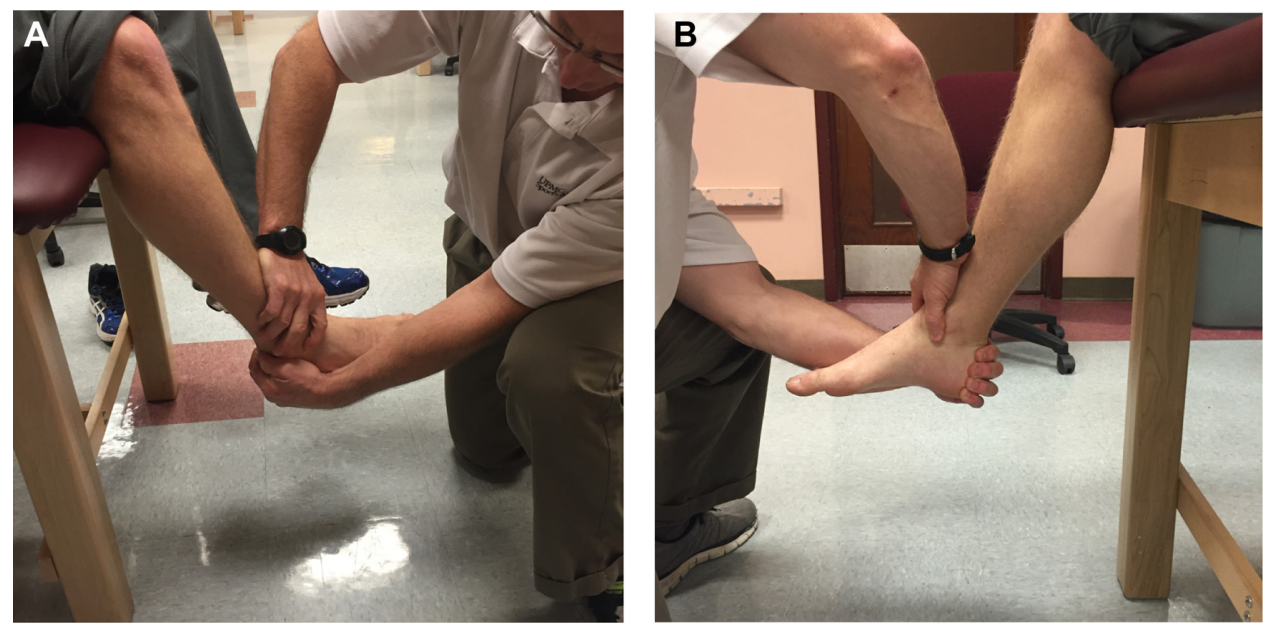

Figure 2 Anterior drawer test for anterior talofibular involvement with (A) lateral and (B) medial view.

inversion force occurs, injury to the lateral forefoot region known as cuboid syndrome can result. ${ }^{16}$ Cuboid syndrome is associated with pain and swelling over the dorsolateral region of the foot. Clinically, it can be identified with the midtarsal adduction test. ${ }^{16}$ OCD lesions can also occur with traumatic sports-related ankle injuries. ${ }^{17-19}$ Athletes with OCD lesions typically have persistent pain, instability, crepitus, and/or locking symptoms that do not improve after 4-6 weeks of conservative treatment. Proper diagnosis of OCD lesions typically requires the use of magnetic resonance imaging. ${ }^{20}$

\section{Diagnosis of lateral ankle sprain and chronic ankle instability}

After ruling out the involvement of other structures around the ankle region, specific evaluation techniques directed at impairments associated with a lateral ankle sprain should be performed. An evaluation of an athlete with a lateral ankle sprain should include an assessment of ecchymosis/hemorrhaging, swelling, point tenderness, ankle range of motion, ligamentous laxity, strength, and overall pain. ${ }^{8,21}$ In addition, an evaluation of the athlete's level of function relating to sports-specific activity should also be completed. ${ }^{8}$ The ability of the clinician to objectively interpret these findings is vital to proper injury grading. A system to assess and grade the severity of an ankle sprain has been developed and is defined as follows: Grade I - no loss of function, no ligamentous laxity (ie, negative anterior drawer and talar tilt tests), little or no hemorrhaging, no point tenderness, decreased total ankle motion of $\leq 5^{\circ}$, and swelling of $\leq 0.5 \mathrm{~cm}$; Grade II - some loss of function, positive anterior drawer test (ATFL involvement), negative talar tilt test (no CFL involvement), hemorrhaging, point tenderness, decreased total ankle motion $>5^{\circ}$ but $<10^{\circ}$, and swelling $>0.5 \mathrm{~cm}$ but $<2.0 \mathrm{~cm}$; Grade III - near total loss of function, positive anterior drawer (Figure 2) and talar tilt tests (Figure 3), hemorrhaging, extreme point tenderness, decreased total ankle motion $>10^{\circ}$, and swelling $>2.0 \mathrm{~cm} .{ }^{21}$ Grade III injuries have been further divided according to stress radiograph results, with anterior drawer movement of $\leq 3 \mathrm{~mm}$ being IIIA and $>3 \mathrm{~mm}$ of movement being IIIB. ${ }^{21}$ This grading system has been validated as the more severe the grade of sprain, the longer it takes the athlete to fully recover. ${ }^{21}$ This emphasizes the importance of an appropriate evaluation and how proper grading regarding the severity of an acute injury can allow for judging injury prognosis.

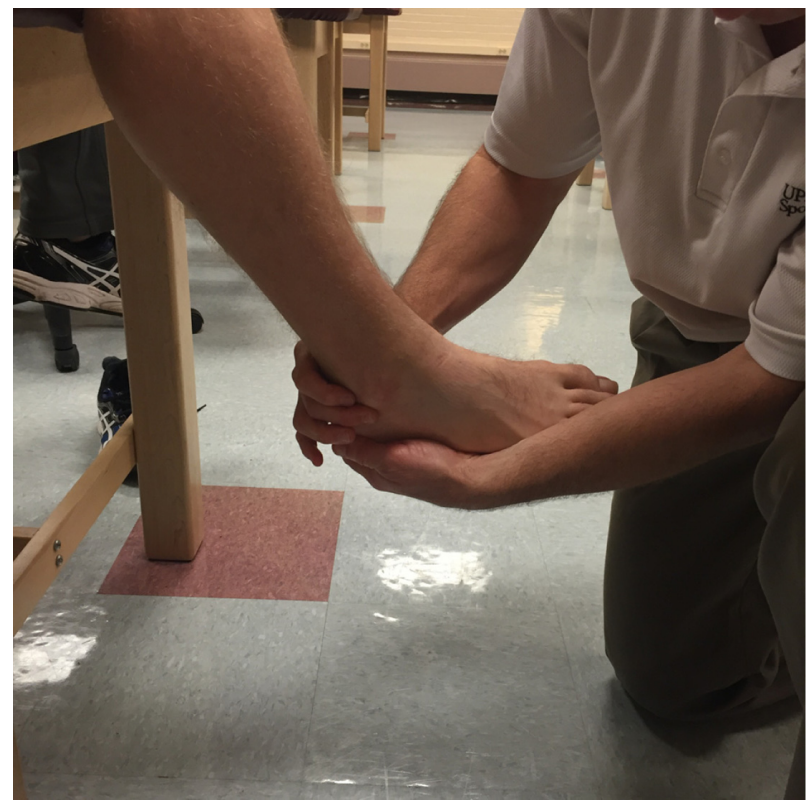

Figure 3 Talar tilt test for calcaneofibular ligament involvement. 
When athletes present with long-term episodes of giving way after sustaining a lateral ankle sprain, they are commonly diagnosed as having either mechanical or functional chronic ankle instability (CAI). ${ }^{22}$ Diagnosing CAI is often difficult and usually relies on subjective complaints and the use of discriminative instruments. ${ }^{8}$ The Cumberland Ankle Instability Too $^{23}$ and Ankle Instability Index ${ }^{24}$ are examples of two such instruments. Categorizing athletes into mechanical or functional CAI subsets has not been consistently defined in literature. ${ }^{25}$ Hertel $^{22}$ notes that these two categories may not be distinct entities. It has been hypothesized that an interaction of mechanical and functional instability occurs leading to several subgroups of CAI. ${ }^{26}$ Recently, the International Ankle Consortium attempted to define CAI in an effort to standardize future research studies. ${ }^{27}$ According to these criteria, those with CAI need to have a history of "giving way" and/or "feelings of instability" from a significant ankle sprain that was associated with an inflammatory response and at least one missed day of activity. Additionally, there needs to be a loss of function as noted by cut-off scores using a self-report instrument, such as the Foot and Ankle Ability Measure (FAAM) ${ }^{27} \mathrm{~A}$ summary of the criteria recommended for defining CAI as put forth by the International Ankle Consortium is presented in Table 1 . The ability of the clinician to personalize rehabilitation programs may improve with continued advancements in identifying those with CAI and defining subgroups within CAI.

\section{Objective assessment/measures}

Whether evaluating an athlete with an acute lateral ankle sprain or CAI, a thorough assessment using objective measures should be completed. Athletes who sustain a lateral ankle sprain may present with pain, decreased function, instability, weakness, stiffness, and swelling, and therefore, an assessment of each should be performed. Typically, an assessment of a lateral ligament injury includes anterior drawer and talar tilt tests. It should be noted that these tests used to assess ligament stability have not shown desirable diagnostic accuracy when done in isolation. ${ }^{28-30}$ Along with an evaluation of impairments, a measurement of activity and participation should also be implemented. ${ }^{8}$ Self-report outcome instruments will give the clinician an idea of the athlete's perceived functional limitations and should be used throughout the rehabilitation process. Several instruments have been developed to assess an athlete's level of activity and participation. The FAAM, Foot and Ankle Disability Index, and Lower Extremity Functional Scale are examples of three such instruments. ${ }^{31}$ The potential advantage of
Table I A summary of the criteria recommended for defining CAl by the International Ankle Consortium

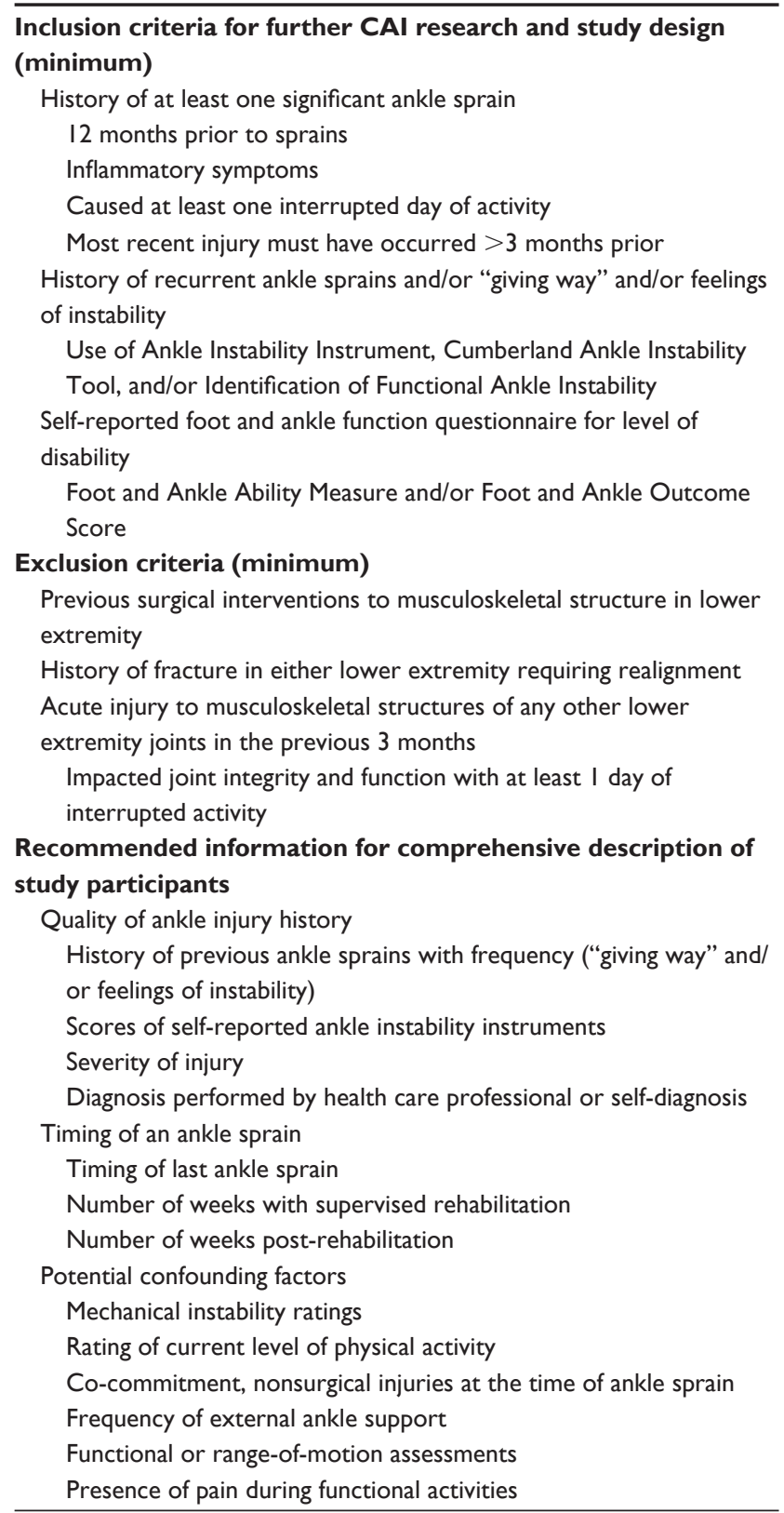

Abbreviation: CAl, chronic ankle instability.

FAAM and Foot and Ankle Disability Index is that they are foot- and ankle region-specific instruments that can assess sport-specific activities in a separately scored subscale. ${ }^{31,32}$ Regardless of which functional outcome measure is utilized, it should be incorporated throughout the rehabilitation process to assess the effect of treatment.

Following a lateral ankle sprain, functional measures that integrate neuromuscular control, strength, range of motion, and proprioception should be included as part of the assessment process. ${ }^{8}$ Functional measures of athletic performance 
should include lateral, diagonal, and change of direction movements. Lateral hopping for distance was found to be particularly useful for those with acute lateral ankle sprains. ${ }^{33,34}$ This measure is performed by having the individual hop as far as possible in a lateral direction with three continuous hops on the involved leg. If a patient is unable to perform the test, he/she is given a score of $0 .{ }^{33}$ While there are several objective measures of jumping activity, such as the single leg hop, side hop, figure-eight hop, $6 \mathrm{~m}$ crossover hop, and square hop, not all are effective in evaluating athletes with CAI. The usefulness of these measures in those with CAI may relate to whether or not the symptoms of instability are reproduced during the test. ${ }^{8}$ Objectively assessing the functional performance of an athlete helps to ensure that those with an ankle injury are being managed in an efficient manner to promote a successful return to activity.

\section{Intervention}

Following objective assessment, the clinician can develop an intervention plan that includes decisions based on the severity of the injury. For most Grade I, II, and III lateral ankle sprains, a nonsurgical management plan has been proven to be effective. ${ }^{35}$ The weight bearing and bracing options of each individual should be addressed depending on the severity of the ankle sprain. Long-term immobilization should be avoided, while short-term immobilization has been shown to be beneficial regardless of severity. ${ }^{35}$ The incorporation of early manual therapy such as soft tissue massage and joint mobilizations can be used to decrease stiffness and swelling while increasing range of motion. ${ }^{36}$ Physical agents used in conjunction with these manual therapy techniques can increase the return to normal gait and progression to therapeutic exercise. Along with this return to normal, active range of motion, a balance and strength training program will enable the gradual return to activity. Each individual injury should be assessed based on severity with a focus on interventions that will effectively decrease the occurrence of reinjury.

A systematic review conducted by Kerkhoffs et $\mathrm{al}^{37}$ found that early weight bearing with support improved the overall resolution of symptoms associated with a lateral ankle sprain. This early weight bearing progression should incorporate an appropriate gait-assistive device and bracing, as needed. ${ }^{8}$ Several studies have shown that incorporating early weight bearing and movement improve the return to normal activity. ${ }^{37-39}$ Early weight bearing and movement have also had effects on restoring normal range of motion and decreasing swelling. ${ }^{37,38}$ Even in those with severe Grade III lateral ankle sprains, early weight bearing and movement improved recovery of ankle mobility and produced a quicker return to activity without affecting long-term mechanical stability. ${ }^{40}$ Support in the form of bracing should be directed at preventing painful ankle motion. Early bracing using below-knee casting and semirigid support have been shown to decrease symptoms and disability. ${ }^{35,41}$ The use of lace-up braces has produced a greater reduction in short-term swelling and disability compared to semirigid bracing. ${ }^{37}$ Overall, the use of bracing has been shown to improve function and decrease symptoms in those who sustain an acute lateral ankle sprain. ${ }^{42}$ Regardless of which bracing technique is incorporated in an athlete's program, bracing choice should be based on the severity of the injury, phase of tissue healing, level of protection indicated, extent of pain, and preference of the injured athlete. ${ }^{8}$ The ability of the athlete to begin movement as early and safely as possible is beneficial to the resolution of symptoms associated with a lateral ankle sprain.

Similar to early weight bearing with support, manual therapy has been shown to improve the overall resolution of a lateral ankle sprain. Restoring motion, decreasing pain, and decreasing swelling can facilitate a return to normal activity level. ${ }^{36}$ Decreasing swelling around the ankle using manual lymphatic drainage techniques can increase the athlete's proprioceptive awareness as well as decrease the risk of ankle stiffness. ${ }^{36}$ Lymphatic drainage techniques can incorporate gravity as well as manually applied massage techniques. Soft tissue and joint mobilizations have been used to improve ankle range of motion. Active mobilization in subjects with Grade II lateral ankle sprains has produced an increase in talocrural dorsiflexion range of motion. ${ }^{43}$ Low-grade passive anterior-posterior glide of the talus in relation to the talocrural joint (Figure 4) was found to increase dorsiflexion

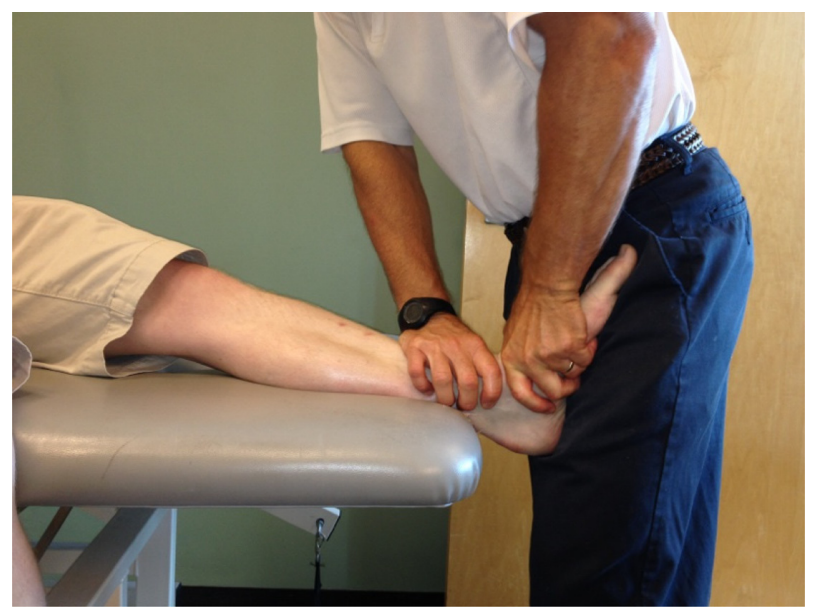

Figure 4 Low-grade passive anterior-posterior glide of the talus. 


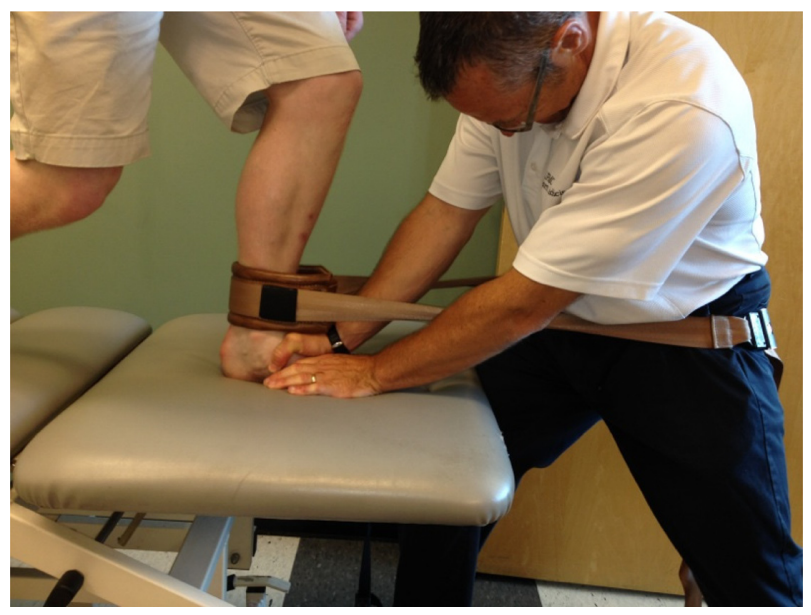

Figure 5 Weight bearing ankle mobilization with movement.

range of motion as well as facilitate a normal stride with gait. ${ }^{44}$ Mobilization with movement applied to the ankle joint incorporates a combination of active dorsiflexion and posterior talar glide mobilization and can be done with the athlete in weight bearing (Figure 5) or non-weight bearing position. ${ }^{45}$ The non-weight bearing mobilization with movement technique may also include distraction using elastic bands (Figure 6). Vicenzino et $\mathrm{al}^{45}$ found that weight bearing and non-weight bearing mobilizations with movement improved posterior talar glide deficits and weight bearing dorsiflexion range of motion when compared to a control group. The mobilization with movement technique also appears to be an effective intervention to restore ankle function in those with CAI. Range of motion, subjective feeling of instability, and dynamic postural control can improve as a result of joint mobilization. ${ }^{46}$ Based on the available evidence, clinicians should include manual therapy techniques into their rehabilitation program in those with acute lateral ankle sprains as well as those with CAI. ${ }^{8}$

In addition to manual therapy, physical agents can also be used to address pain and swelling that result from a lateral ankle sprain. Cryotherapy is a physical agent widely accepted for use in the acute phase of healing to decrease pain and manage swelling. The use of ice in addition to exercise in management of acute lower extremity injuries was found to be beneficial in decreasing pain, increasing weight bearing ability, and decreasing the use of prescription and nonprescription medication. ${ }^{47}$ Intermittent immersion cryotherapy treatments over a 1-week period were found to be more effective in the short-term reduction of pain with activity when compared to one 20-minute cryotherapy application. ${ }^{48}$ Ice in conjunction with compression has also been shown to significantly decrease pain. ${ }^{49}$ Another physical agent that has been shown to reduce swelling is pulsed shortwave diathermy. The use of this physical agent was also shown to improve a subjective assessment of limping in individuals with an acute ankle sprain. ${ }^{50}$ As it relates to physical agents, a recent review found strong evidence to support cryotherapy, weak evidence to support pulsed shortwave diathermy, conflicting evidence for electrotherapy and low-level laser, and strong evidence against the use of ultrasound for the management of acute ankle sprains. ${ }^{8}$

An intervention plan that successfully decreases pain and swelling may enable the athlete to begin a progressive therapeutic exercise program. Therapeutic exercises that begin early in the rehabilitation process and focus on increasing ankle range of motion, strengthening the surrounding muscles, and restoring neuromuscular control have been shown to improve lower extremity function. ${ }^{51-53}$ Therapeutic exercise combined with conventional treatment, consisting of ice, compression, and elevation, was shown to have a significant improvement over conventional treatment alone. ${ }^{52}$ Therapeutic exercise for an acute ankle sprain includes balance training. Holme et $\mathrm{al}^{54}$ initiated a balance and strength training program within the first week after an acute ankle sprain and found that reinjury rate after 1 year was significantly reduced compared to a control group. For those with CAI, the use of an unstable
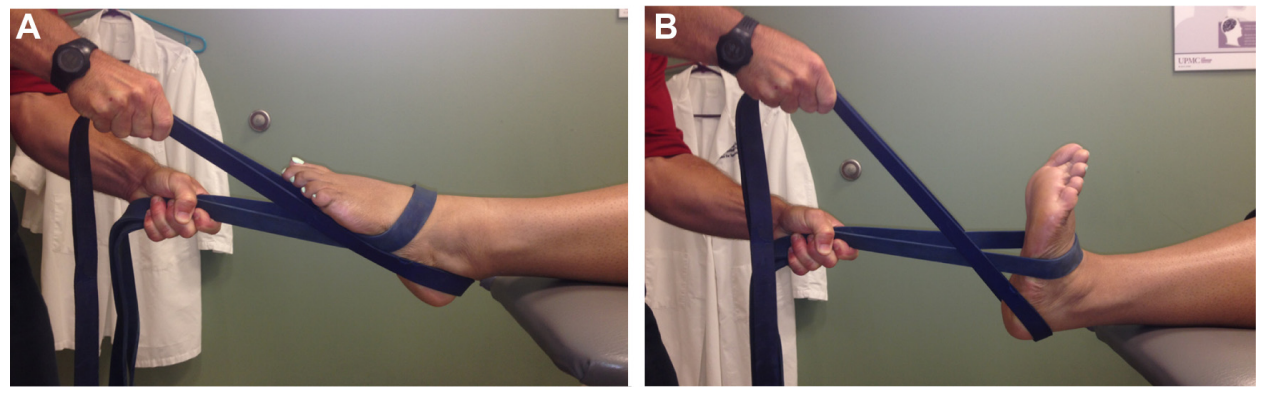

Figure 6 Non-weight bearing ankle distraction mobilization using elastic bands with movement from a (A) plantar flexed position to a (B) dorsiflexion position. 
surface while performing functional exercises was found to improve dynamic postural control. ${ }^{55}$ Balance training with a wobble board has also been shown to improve functional performance, improve postural control, and decrease the risk of recurrence in those with CAI. ${ }^{56}$

As an athlete progresses through a strength and balance training program, it may be important to incorporate exercises that include proximal musculature of the hip and trunk. Deficiencies in hip strength have been shown to increase the risk of lateral ankle sprains. ${ }^{57}$ Decreased gluteal activation and strength have been demonstrated in individuals with CAI during electromyography monitoring. ${ }^{58,59}$ Incorporating trunk and hip strengthening exercises in a rehabilitation program may help to decrease the risk of reinjury and therefore should be included in those with an acute lateral ankle sprain as well as those with CAI. There has not been significant research to prove that sports-specific training is more effective than balance training in regards to diminishing risk of reinjury. However, based on weak evidence, it is recommended that sports-related training be included in a therapeutic exercise program for athletes with acute injuries as well as those with $\mathrm{CAI} .{ }^{8}$ As an example, sports-related training drills could be done in a speed ladder as provided in Table 2. Restoration of mobility, strength, proprioceptive control, and coordination while performing sports-related training may assist the athletes in returning to their respective sport while also reducing their risk for future injury.

Table 2 An example of sports-related training drills to be done with a speed ladder

Straightforward running with one foot in each box
Straightforward running with both feet in each box
High knees straightforward running with one foot in each box
High knees straightforward running with both feet in each box
Lateral shuffle with both feet in each box (repetition with both right
and left side leading)
High knees lateral shuffle with both feet in each box (repetition with
both right and left side leading)
On the side facing the ladder - alternating both feet in each box
followed by both feet outside of box while moving down the ladder.
This will be a forward-backward-forward motion as you move down
the ladder (repetition with both right and left side leading)
Icky shuffle - moving left to right and back to left. Start with
alternating right and left foot in each box. Plant with right foot outside
of box
Followed by left and right foot in second box. Plant with left foot
outside of box. Continue this while moving up the ladder
Lateral carioca motion with one foot in each box (repetition with
both right and left side leading)
Lateral carioca motion with both feet in each box (repetition with
both right and left side leading)

Straightforward running with one foot in each box

High knees straightforward running with one foot in each box

High knees straightforward running with both feet in each box

Lateral shuffle with both feet in each box (repetition with both right both right and left side leading)

On the side facing the ladder - alternating both feet in each box followed by both feet outside of box while moving down the ladder.

ove down the ladder (repetition with both right and left side leading) Icky shuffle - moving left to right and back to left. Start with alternating right and left foot in each box. Plant with right foot outside

Followed by left and right foot in second box. Plant with left foot outside of box. Continue this while moving up the ladde Lateral carioca motion with one foot in each box (repetition with Lateral carioca motion with both feet in each box (repetition with teading)

\section{Clinical course}

It is essential to understand the normal clinical course for athletes who sustain a lateral ankle sprain as well as risk factors for an acute injury and CAI. An evidence-based treatment approach should be used to address impairments relating to swelling, pain, weakness, range-of-motion limitations, and loss of function. Identifying possible factors that could lead to the failure of full recovery or reinjury is also required. Predisposing factors that increase the risk of lateral ankle sprains should also be identified in preventive management. A moderate level of evidence identified an increased risk of an acute lateral ankle sprain in individuals who (1) have a history of previous ankle sprain, (2) do not prophylactically use an external ankle support, (3) do not properly warm up with either static stretching or dynamic movements before engaging in physical activity, (4) do not have normal dorsiflexion range of motion, and (5) do not participate in a balance prevention program when history of previous injury is present. ${ }^{8}$ For those who sustain an acute Grade I, II, IIIA, or IIIB lateral ankle sprain, it was reported that full recovery occurred on average within 7.2, 15.0, 30.7, and 55.4 days, respectively. ${ }^{21}$ A systematic review performed by van Rijn et $a l^{60}$ found that patients who were treated for acute lateral ankle sprains with a conventional protocol had a general decrease in pain and improvement in motion and function within 2 weeks after the initial injury. ${ }^{60}$ The result of a 1-year follow-up, however, showed that $5 \%-25 \%$ were still experiencing pain or episodes of instability. At 3 years, 34\% of the participants reported an incident of reinjury. ${ }^{60}$ Residual issues relating to acute ankle sprains that were present after 1 year included pain $(30 \%)$, instability $(20 \%)$, crepitus $(18 \%)$, weakness $(17 \%)$, stiffness (15\%), and swelling (14\%). ${ }^{61}$ Along with these issues, sensorimotor deficits can also occur. The deficits in individuals who sustain a lateral ankle sprain include proprioception, postural control, reflex reactions to inversion perturbations, alpha motor neuron pool excitability, and strength of surrounding musculature. ${ }^{62}$ These residual deficits may put an athlete at risk for reinjury and/or CAI. Weak evidence found an increase of ankle instability in those who (1) have an increased talar curve, (2) are not using an external support, or (3) did not perform balance or proprioception exercises following an acute lateral ankle sprain. ${ }^{8}$ The systemic review performed by van Rijn et al ${ }^{60}$ also found that individuals who were involved with high levels of activity were at increased risk for developing CAI. The more likely an individual is to engage in activity, the higher the likelihood that he/she will experience symptoms, 
especially when external bracing is not used and/or preventative balance exercises are not performed. ${ }^{8}$

Surgical intervention may be indicated when symptoms are unresolved with conservative treatment. A review of 12 trials comparing surgical to nonsurgical intervention overall showed no significant evidence to recommend conservative or surgical interventions when treating an individual with an acute lateral ankle sprain. ${ }^{63}$ Another study performed by Pihlajamaki et $\mathrm{al}^{64}$ showed that the long-term effects of surgical treatment of acute lateral ankle sprains are comparable to the conservative treatment in physically active males. Overall, it appears that surgery may increase the risk of posttraumatic osteoarthritis but decrease the risk of reinjury. ${ }^{64}$

\section{New perspectives/ future research directions}

As research continues to progress, incorporating new evidence-based rehabilitation techniques will give clinicians the ability to provide the best course of treatment for athletes with acute lateral ankle sprains or CAI. Areas of new research include treatment directed at upper extremity postural control, fibular positioning, and trigger point dry needling. It is believed that inclusion of upper extremity postural control exercises may be important due to possible deficits in the central sensorimotor integration and processing in individuals with CAI ${ }^{65} \mathrm{~A}$ recent study found that individuals with CAI did not demonstrate a correlation in upper and lower limb postural control that was observed in the healthy controls. This may support interventions that address coordination of the upper extremity during ankle rehabilitation as a preventative measure against reinjury. ${ }^{65}$ The role of fibular malpositioning after a lateral ankle sprain has been debated. Mulligan athletic taping is a technique directed at fibular repositioning (Figure 7). The rationale behind this intervention is that those with CAI have an anterior positional fault of the fibula that can be corrected with taping. A recent study found that Mulligan athletic taping improved performance on functional testing in athletes with CAI. ${ }^{66}$ Treatment that could improve muscle control deficits that present after ankle sprains may improve treatment outcomes in those with acute lateral ankle sprains or CAI. Trigger points in the peroneal muscles may occur after repetitive ankle sprains and alter normal motor control patterns. Dry needling has been a proposed treatment to address trigger points and the negative effects associated with them. A recent study provided evidence that when trigger point dry needling directed at the lateral peroneus muscle was

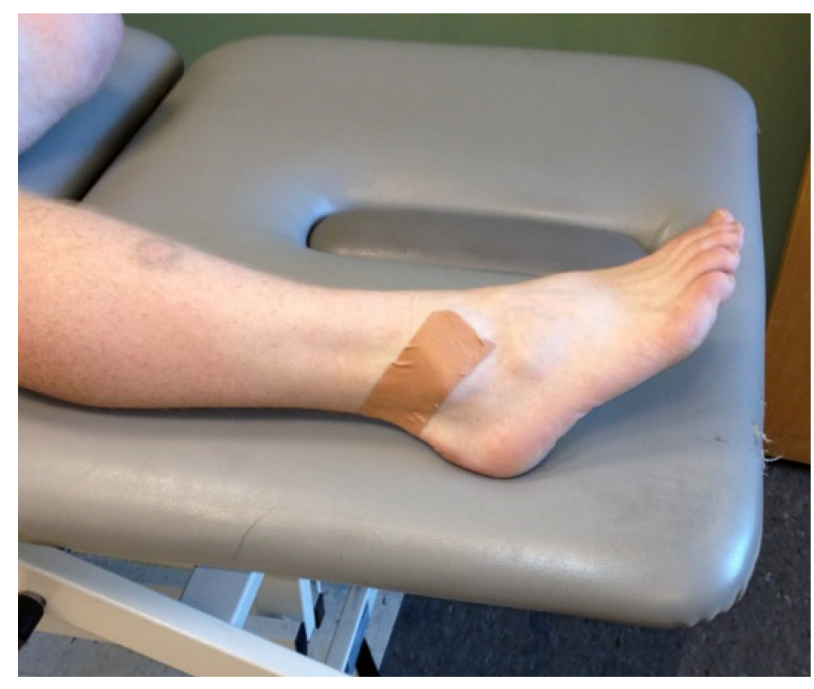

Figure 7 Fibular repositioning taping technique.

added to an exercise program, an improvement in function and decrease in pain resulted. ${ }^{67}$

\section{Conclusion}

Ankle sprains continue to be one of the most prevalent orthopedic injuries in athletics. Appropriate evidencebased management of athletes with an acute lateral ankle sprain or CAI should be employed to allow for a successful return to sports. This includes an understanding of current knowledge as it relates to pathoanatomical features, diagnosis, objective assessment, intervention, and clinical course. Evidence finds that an appropriate evaluation is needed not only to determine the correct diagnosis but also to allow for grading severity and determining the prognosis of the injury in those with an acute lateral ankle sprain. Examination should include an assessment of impairments as well as a measure of activity and participation. An evidence-based treatment approach should be used to address impairments relating to swelling, pain, range of motion, weakness, and loss of function. Interventions for those with an acute lateral ankle sprain should include weight bearing with bracing, manual therapy, progressive therapeutic exercises, and cryotherapy. For those with CAI, interventions should include manual therapy and a comprehensive rehabilitation program. It is essential to understand the normal clinical course for athletes who sustain a lateral ankle sprain as well as risk factors for an acute injury and CAI. Risk factors for both an acute lateral ankle sprain and CAI include not using an external support and not participating in an appropriate exercise program. Knowledge and use of the latest evidence-based rehabilitation techniques provide 
the best course of treatment for athletes with acute lateral ankle sprains or CAI.

\section{Disclosure}

The authors report no conflicts of interest in this work.

\section{References}

1. Doherty C, Delahunt E, Caulfield B, Hertel J, Ryan J, Bleakley C. The incidence and prevalence of ankle sprain injury: a systematic review and meta-analysis of prospective epidemiological studies. Sports Med. 2014;44(1):123-140.

2. Fong DT, Hong Y, Chan LK, Yung PS, Chan KM. A systematic review on ankle injury and ankle sprain in sports. Sports Med. 2007;37(1):73-94.

3. McKay GD, Goldie PA, Payne WR, Oakes BW, Watson LF. A prospective study of injuries in basketball: a total profile and comparison by gender and standard of competition. J Sci Med Sport. 2001;4(2):196-211.

4. Fong DT, Man CY, Yung PS, Cheung SY, Chan KM. Sport-related ankle injuries attending an accident and emergency department. Injury. 2008;39(10):1222-1227.

5. McKay GD, Goldie PA, Payne WR, Oakes BW. Ankle injuries in basketball: injury rate and risk factors. Br J Sports Med. 2001;35(2):103-108.

6. Bahr R, Karlsen R, Lian O, Ovrebo RV. Incidence and mechanisms of acute ankle inversion injuries in volleyball. A retrospective cohort study Am J Sports Med. 1994;22(5):595-600.

7. Smith RW, Reischl SF. Treatment of ankle sprains in young athletes. Am J Sports Med. 1986;14(6):465-471.

8. Martin RL, Davenport TE, Paulseth S, Wukich DK, Godges JJ; Orthopaedic Section American Physical Therapy Association. Ankle stability and movement coordination impairments: ankle ligament sprains. J Orthop Sports Phys Ther. 2013;43(9):A1-A40.

9. Stiell IG, Greenberg GH, McKnight RD, Wells GA. Ottawa ankle rules for radiography of acute injuries. N Z Med J. 1995;108(996):111.

10. Xenos JS, Hopkinson WJ, Mulligan ME, Olson EJ, Popovic NA. The tibiofibular syndesmosis. Evaluation of the ligamentous structures, methods of fixation, and radiographic assessment. J Bone Joint Surg Am. 1995;77(6):847-856.

11. Williams GN, Jones MH, Amendola A. Syndesmotic ankle sprains in athletes. Am J Sports Med. 2007;35(7):1197-1207.

12. Alonso A, Khoury L, Adams R. Clinical tests for ankle syndesmosis injury: reliability and prediction of return to function. J Orthop Sports Phys Ther. 1998;27(4):276-284.

13. Nussbaum ED, Hosea TM, Sieler SD, Incremona BR, Kessler DE. Prospective evaluation of syndesmotic ankle sprains without diastasis. Am J Sports Med. 2001;29(1):31-35.

14. Grossterlinden LG, Hartel M, Yamamura J, et al. Isolated syndesmotic injuries in acute ankle sprains: diagnostic significance of clinical examination and MRI. Knee Surg Sports Traumatol Arthrosc. Epub Apr 21, 2015.

15. Lynch SA. Assessment of the injured ankle in the athlete. J Athl Train. 2002;37(4):406-412.

16. Jennings J, Davies GJ. Treatment of cuboid syndrome secondary to lateral ankle sprains: a case series. J Orthop Sports Phys Ther. 2005;35(7):409-415

17. Harrington KD. Degenerative arthritis of the ankle secondary to long-standing lateral ligament instability. J Bone Joint Surg Am. 1979;61(3):354-361.

18. Hintermann B, Boss A, Schafer D. Arthroscopic findings in patients with chronic ankle instability. Am J Sports Med. 2002;30(3):402-409.

19. Valderrabano V, Hintermann B, Horisberger M, Fung TS. Ligamentous posttraumatic ankle osteoarthritis. Am J Sports Med. 2006;34(4):612-620.

20. Campbell SE, Warner M. MR imaging of ankle inversion injuries. Magn Reson Imaging Clin N Am. 2008;16(1):1-18, v.
21. Malliaropoulos N, Papacostas E, Papalada A, Maffulli N. Acute lateral ankle sprains in track and field athletes: an expanded classification. Foot Ankle Clin. 2006;11(3):497-507.

22. Hertel J. Functional anatomy, pathomechanics, and pathophysiology of lateral ankle instability. $J$ Athl Train. 2002;37(4):364-375.

23. Hiller CE, Refshauge KM, Bundy AC, Herbert RD, Kilbreath SL. The Cumberland ankle instability tool: a report of validity and reliability testing. Arch Phys Med Rehabil. 2006;87(9):1235-1241.

24. Docherty CL, Gansneder BM, Arnold BL, Hurwitz SR. Development and reliability of the ankle instability instrument. J Athl Train. 2006; 41(2):154-158.

25. Delahunt E, Coughlan GF, Caulfield B, Nightingale EJ, Lin CW, Hiller $\mathrm{CE}$. Inclusion criteria when investigating insufficiencies in chronic ankle instability. Med Sci Sports Exerc. 2010;42(11):2106-2121.

26. Hiller CE, Kilbreath SL, Refshauge KM. Chronic ankle instability: evolution of the model. J Athl Train. 2011;46(2):133-141.

27. Gribble PA, Delahunt E, Bleakley C, et al. Selection criteria for patients with chronic ankle instability in controlled research: a position statement of the International Ankle Consortium. Br J Sports Med. 2014;48(13):1014-1018.

28. Hertel J, Denegar CR, Monroe MM, Stokes WL. Talocrural and subtalar joint instability after lateral ankle sprain. Med Sci Sports Exerc. 1999;31(11):1501-1508.

29. Raatikainen T, Putkonen M, Puranen J. Arthrography, clinical examination, and stress radiograph in the diagnosis of acute injury to the lateral ligaments of the ankle. Am J Sports Med. 1992;20(1):2-6.

30. van Dijk CN, Lim LS, Bossuyt PM, Marti RK. Physical examination is sufficient for the diagnosis of sprained ankles. J Bone Joint Surg Br. 1996;78(6):958-962.

31. Martin RL, Irrgang JJ. A survey of self-reported outcome instruments for the foot and ankle. J Orthop Sports Phys Ther. 2007;37(2): $72-84$.

32. Martin RL, Irrgang JJ, Burdett RG, Conti SF, Van Swearingen JM. Evidence of validity for the Foot and Ankle Ability Measure (FAAM). Foot Ankle Int. 2005;26(11):968-983.

33. Williams GN, Molloy JM, DeBerardino TM, Arciero RA, Taylor DC. Evaluation of the Sports Ankle Rating System in young, athletic individuals with acute lateral ankle sprains. Foot Ankle Int. 2003;24(3):274-282.

34. Gerber JP, Williams GN, Scoville CR, Arciero RA, Taylor DC. Persistent disability associated with ankle sprains: a prospective examination of an athletic population. Foot Ankle Int. 1998;19(10):653-660.

35. Petersen W, Rembitzki IV, Koppenburg AG, et al. Treatment of acute ankle ligament injuries: a systematic review. Arch Orthop Trauma Surg. 2013;133(8):1129-1141.

36. Eisenhart AW, Gaeta TJ, Yens DP. Osteopathic manipulative treatment in the emergency department for patients with acute ankle injuries. J Am Osteopath Assoc. 2003;103(9):417-421.

37. Kerkhoffs GM, Rowe BH, Assendelft WJ, Kelly KD, Struijs PA, van Dijk CN. Immobilisation for acute ankle sprain. A systematic review. Arch Orthop Trauma Surg. 2001;121(8):462-471.

38. Eiff MP, Smith AT, Smith GE. Early mobilization versus immobilization in the treatment of lateral ankle sprains. Am J Sports Med. 1994; 22(1):83-88.

39. Dettori JR, Basmania CJ. Early ankle mobilization, Part II: a one-year follow-up of acute, lateral ankle sprains (a randomized clinical trial). Mil Med. 1994;159(1):20-24.

40. Lynch SA, Renstrom PA. Treatment of acute lateral ankle ligament rupture in the athlete. Conservative versus surgical treatment. Sports Med. 1999;27(1):61-71.

41. Lamb SE, Marsh JL, Hutton JL, Nakash R, Cooke MW Collaborative Ankle Support Trial. Mechanical supports for acute, severe ankle sprain: a pragmatic, multicentre, randomised controlled trial. Lancet. 2009;373(9663):575-581

42. Kemler E, van de Port I, Backx F, van Dijk CN. A systematic review on the treatment of acute ankle sprain: brace versus other functional treatment types. Sports Med. 2011;41(3):185-197. 
43. Collins N, Teys P, Vicenzino B. The initial effects of a Mulligan's mobilization with movement technique on dorsiflexion and pain in subacute ankle sprains. Man Ther. 2004;9(2):77-82.

44. Green T, Refshauge K, Crosbie J, Adams R. A randomized controlled trial of a passive accessory joint mobilization on acute ankle inversion sprains. Phys Ther. 2001;81(4):984-994.

45. Vicenzino B, Branjerdporn M, Teys P, Jordan K. Initial changes in posterior talar glide and dorsiflexion of the ankle after mobilization with movement in individuals with recurrent ankle sprain. J Orthop Sports Phys Ther. 2006;36(7):464-471.

46. Cruz-Diaz D, Lomas Vega R, Osuna-Perez MC, Hita-Contreras F, Martinez-Amat A. Effects of joint mobilization on chronic ankle instability: a randomized controlled trial. Disabil Rehabil. 2015;37(7): 601-610.

47. Bleakley C, McDonough S, MacAuley D. The use of ice in the treatment of acute soft-tissue injury: a systematic review of randomized controlled trials. Am J Sports Med. 2004;32(1):251-261.

48. Bleakley CM, McDonough SM, MacAuley DC, Bjordal J. Cryotherapy for acute ankle sprains: a randomised controlled study of two different icing protocols. Br J Sports Med. 2006;40(8):700-705; discussion 705.

49. Hubbard TJ, Denegar CR. Does cryotherapy improve outcomes with soft tissue injury? J Athl Train. 2004;39(3):278-279.

50. Pasila M, Visuri T, Sundholm A. Pulsating shortwave diathermy: value in treatment of recent ankle and foot sprains. Arch Phys Med Rehabil. 1978;59(8):383-386.

51. Hale SA, Hertel J, Olmsted-Kramer LC. The effect of a 4-week comprehensive rehabilitation program on postural control and lower extremity function in individuals with chronic ankle instability. J Orthop Sports Phys Ther. 2007;37(6):303-311.

52. van Rijn RM, van Heest JA, van der Wees P, Koes BW, Bierma-Zeinstra SM. Some benefit from physiotherapy intervention in the subgroup of patients with severe ankle sprain as determined by the ankle function score: a randomised trial. Aust J Physiother. 2009;55(2):107-113.

53. Bleakley CM, O'Connor SR, Tully MA, et al. Effect of accelerated rehabilitation on function after ankle sprain: randomised controlled trial. BMJ. 2010;340:c1964.

54. Holme E, Magnusson SP, Becher K, Bieler T, Aagaard P, Kjaer M. The effect of supervised rehabilitation on strength, postural sway, position sense and re-injury risk after acute ankle ligament sprain. Scand J Med Sci Sports. 1999;9(2):104-109.

55. Webster KA, Gribble PA. Functional rehabilitation interventions for chronic ankle instability: a systematic review. J Sport Rehabil. 2010;19(1):98-114
56. Wester JU, Jespersen SM, Nielsen KD, Neumann L. Wobble board training after partial sprains of the lateral ligaments of the ankle: a prospective randomized study. J Orthop Sports Phys Ther. 1996;23(5): 332-336.

57. McHugh MP, Tyler TF, Tetro DT, Mullaney MJ, Nicholas SJ. Risk factors for noncontact ankle sprains in high school athletes: the role of hip strength and balance ability. Am J Sports Med. 2006;34(3):464-470.

58. Bullock-Saxton JE, Janda V, Bullock MI. The influence of ankle sprain injury on muscle activation during hip extension. Int J Sports Med. 1994;15(6):330-334.

59. Beckman SM, Buchanan TS. Ankle inversion injury and hypermobility: effect on hip and ankle muscle electromyography onset latency. Arch Phys Med Rehabil. 1995;76(12):1138-1143.

60. van Rijn RM, van Os AG, Bernsen RM, Luijsterburg PA, Koes BW, Bierma-Zeinstra SM. What is the clinical course of acute ankle sprains? A systematic literature review. Am J Med. 2008;121(4):324-331.e6.

61. Fong DT, Chan YY, Mok KM, Yung P, Chan KM. Understanding acute ankle ligamentous sprain injury in sports. Sports Med Arthrosc Rehabil Ther Technol. 2009;1:14.

62. Hertel J. Sensorimotor deficits with ankle sprains and chronic ankle instability. Clin Sports Med. 2008;27(3):353-370, vii.

63. Kerkhoffs GM, Handoll HH, de Bie R, Rowe BH, Struijs PA. Surgical versus conservative treatment for acute injuries of the lateral ligament complex of the ankle in adults. Cochrane Database Syst Rev. 2007;(2):CD000380.

64. Pihlajamaki H, Hietaniemi K, Paavola M, Visuri T, Mattila VM. Surgical versus functional treatment for acute ruptures of the lateral ligament complex of the ankle in young men: a randomized controlled trial. J Bone Joint Surg Am. 2010;92(14):2367-2374.

65. Springer S, Gottlieb U, Moran U, Verhovsky G, Yanovich R. The correlation between postural control and upper limb position sense in people with chronic ankle instability. J Foot Ankle Res. 2015;8:23.

66. Someeh M, Norasteh AA, Daneshmandi H, Asadi A. Immediate effects of Mulligan's repositioning taping on postural control in athletes with and without chronic ankle instability. Phys Ther Sport. 2015;16(2):135-139.

67. Salom-Moreno J, Ayuso-Casado B, Tamaral-Costa B, Sanchez-Mila Z, Fernandez-de-Las-Penas C, Alburquerque-Sendin F. Trigger point dry needling and proprioceptive exercises for the management of chronic ankle instability: a randomized clinical trial. Evid Based Complement Alternat Med. 2015;2015:790209.
Open Access Journal of Sports Medicine

\section{Publish your work in this journal}

Open Access Journal of Sports Medicine is an international, peer-reviewed, open access journal publishing original research, reports, reviews and commentaries on all areas of sports medicine. The manuscript management system is completely online and includes a very quick and fair peer-review system.

\section{Dovepress}

Visit http://www.dovepress.com/testimonials.php to read real quotes from published authors. 